\title{
Comparison of working memory and sensory profile in boys and girls with writing disability
}

\author{
Alireza Sangani* ${ }^{\mathbb{D}}$, Paria Jangi
}

Ph.D. in Psychology and Exceptional Children Education, Assistant Professor, Department of Psychology, Ahvaz Branch, Islamic Azad University, Ahvaz, Iran

*Corresponding Author: Alireza Sangani, Ph.D. in Educational Psychology, Department of Psychology, Assistant Professor, Science and Research, Islamic Azad University, Tehran, Iran. Tel: 09112682404, 06133348420, Fax: 06133329200, E-mail: paria.jangi@yahoo.com

\begin{abstract}
Background and aims: Children with learning disabilities mainly have problems in cognition and sensations. Therefore, this study aimed to compare working memory and sensory profile in boys and girls with writing disability.

Methods: To this end, this descriptive study applied a comparative method to collect the required data. Statistical population of the study included all girls and boys within the age range of 8-10, who were suffering from writing disability during their treatment in a writing disability center in Gorgan during the summer of 2018. In addition, a stratified random sampling method was used and 50 boys and 58 girls were selected from each group accordingly. Based on the research tools, the Dunn profile (1999) was obtained from the parents of the children. In the area of Daneman and Carpenter working memory (1980), children were directly questioned in order to obtain information related to processing and storage in their memory. Finally, data were analyzed by SPSS software using multivariate analysis of variance analysis.

Results: Based on descriptive findings (i.e., mean and standard deviation), the following data were obtained regarding the intended parameters in boys and girls as processing $(50.32 \pm 6.93,54.22 \pm 7.45)$, storage $(48.47 \pm 6.08,53.17 \pm 6.07)$, indoctrination associated with the physical state of body motion $(34.28 \pm 7.09,36.91 \pm 6.48)$, multisensory processing $(34.68 \pm 5.21,37.94 \pm 6.57)$, and auditory processing $(31.74 \pm 5.84,35.52 \pm 6.59)$, respectively. In addition, the results indicated a significant difference in the writing disability among the processing $(P<0.006)$ and storage $(P<0.000)$ of working memory subscales and indoctrination associated with the physical state of the body motion $(P<0.000)$, multisensory processing $(P<0.000)$, and auditory processing $(P<0.002)$ of the sensory profile in both girls and boys with writing disabilities.

Conclusion: In general, the boys had a worse condition concerning their working memory and sensory processing styles that require special attention and more focused educational approaches.

Keywords: Writing disability; Working memory; Sensory profile
\end{abstract}

Received: 4 March 2019, Accepted: 30 March 2019, ePublished: 30 August 2019

\section{Introduction}

A learning disorder is defined as a neurobiological problem in cognitive processing like memory and language, which is created due to the abnormal function of the brain and can disturb the educational function (1). In recent years, learning disability including writing has been recognized as a type of learning inability with regard to its increasing learning (2). In addition, writing-learning disability is a structural and cognitive problem that disturbs the individual in attaining cognitive processing skills in learning as writing (3). Such types of disabilities are distinguished at the time when the likelihood of the child's writing achievement is lower in a standardized test compared to his/her intelligence and education (4). The recent studies indicate that the weakness of the children with learning disorders in effective memory and encoding processes is more than attention or long-term memory (5). On the other hand, the individual's perception and reaction to the education environment depend on sensory processing and his/her obtained inputs (6). The child is quiet, conscious, concentrated, and ready to play and learn if the sensory processing level is normal (7). Some previous studies showed that sensory processing style is an important factor, and disorders such as hyperactivity, obsession, and sleeping disorders are related to high sensory processing, while illnesses like anxiety, depression, and stress are related to low sensory processing $(8,9)$. On the other hand, learning disorders relate to high and low sensory processing (10). The children with sensory processing problems face such issues as sensitivity to sound, crowd, physical touch, pictures, and the words of the books, which are considered an important factor in more deficiency in learning problems at school (11), and these beguiled inputs

(C) 2019 The Author(s); Published by Shahrekord University of Medical Sciences. This is an open-access article distributed under the terms of the Creative Commons Attribution License (http://creativecommons.org/licenses/by/4.0), which permits unrestricted use, distribution, and reproduction in any medium, provided the original work is properly cited. 
obtained from the environment disturb the storage of basic information in the memory (12). Meanwhile, active memory includes registered information at the permanent memory that is currently in the fully active state and involves the cognitive and underlying process of learning related to the information storage in the mind and its recovery (13). Further, the active memory denotes all temporary information that the individual has access to at any time (14). In addition, some studies demonstrated that active memory plays a significant role in learning disabilities (15).

Swanson and Jerman (16) found that the difference in brain processing of individuals with learning disorders expresses some deficiencies in left hemisphere., Investigating the relationship between a learning disorder and working memory, Shokouhi-Yekta et al found that children with learning disorders have a clear disability in their working memory (14). Furthermore, the processing rate, environmental inputs processing, and working memory could be mentioned among the cognitive factors contributing to the writing-learning disorder (18). Peng and Fuchs (19) and Brandenburg et al (20) reported that there is a difference between the working memory in children with learning disorder based on the role of age and gender. Rodak and Alloway (21) showed that there is a relationship between motion and sensory coordination with working memory, while there is a difference between girls and boys concerning the writing disorder. Moreover, Alloway and Temple (22) found a difference between working memory skills and learning in female and male children with the writing-learning disorder, indicating that the girls' (females') working memory was better than that of the boys. The results of some studies like Mammarella et al (23) and Maehler and Schuchardt (24) indicated that the intensity of working memory deficiency affects the background of learning disorder type and paves the way for the emergence of the disorder in children. Based on the findings of Leong et al (25), there was a difference in the combination of processing the seeing and hearing senses between female and male children with learning disorders. Additionally, some other studies revealed that a series of abnormal functions of brain processing have been diagnosed that play a role in linguistic-auditory processing, especially in quick reading and writing processing $(26,27)$. According to Kirby et al, material processing and quick automatic calling are two core processes that predict writing skills (28). Some individuals with learning disorders have structural differences regarding the visual systems of their brains with common individuals $(29,30)$.

In general, memory abilities and sensory processing are important for an effective response to situations, learning facilitation, social behavior, and daily functions of the individual. Thus, an investigation into working memory deficiencies and sensory processing styles in children with a writing-learning disability seems necessary for better understanding the neuropsychological attributes of these individuals and designing the efficient treatment methods with regard to the gender. Hence, considering the abovementioned issues, the present research mainly sought to compare working memory and sensory profile in boys and girls with writing disabilities.

\section{Methods}

The population of this descriptive-comparative study included all girls and boys with writing disabilities within the age range of $8-10$, who were treated in a writing disability center in Gorgan in 2018. Overall, 150 individuals (including 69 boys and 81 girls with writing disability) were enrolled, out of whom 108 ones were selected by a stratified random sampling method (the sample number of each group was determined based on the population number of each gender group) and based on the Krejcie and Morgan Table. Finally, 50 boys and 58 girls were selected to increase the external validity of the research. Considering the research instruments, Dunn profile (1999) was received from 8-10-year-old children's parents, and concerning the active memory tool area, the children were directly questioned in order to obtain information related to processing and storage in memory. The inclusion criteria include $\mathrm{d}$ learning disability in boys and girls aged 8-10 years, the absence of psychiatric disorders, along with the diagnosis of a psychiatrist based on DSMV (Diagnostic and Statistical Manual of Mental Disorders) criteria, and the completion of an informed consent form for participation by parents. In addition, the exclusion criteria were the in complete completion of the study tools. The written informed consent was obtained from the parents after explaining the research goals and their cooperation procedure. Following the completion of the final tools, the data were finally analyzed by multivariate analysis of variance method using SPSS software, version 24 at the significance level of 0.05 .

Active memory questionnaire w a $s$ developed by Daneman and Carpenter to measure the working memory capacity (31). The above test includes 27 statements, which are classified into six sections ranging from the two-statement part through the seven-statement part. Measuring two sections of wor $\mathrm{k}$ ing memory (i.e., processing and storage) concu r rently, while conducting a mental activity, is considered as the main characteristic of this test. The subjects are asked to carefully listen to a sequence of different and pretty difficult statements in each step and then to do two mental tasks (i.e., processing and storage) concurrently including correctly distinguishing the meaning and concept of the expressed statements and memorizing the last word expressed in the statements (32). The value of all the st a tements is unique (unit) in this test and one single grade (mark) accrues to each correct response. Group-measurer of this tool is from 7 years onward. Similarly, structure and content validity was confirmed by the developers and the reliability was 0.87 , 
0.9, and 0.92 for the Kuder-Richardson method for the sub-scales of processing, storage, and the total. Content and structure validity was determined by Asadzadeh (32) evaluating 84 students of psychology and educational science school of Allameh Tabatabaei University, and the correlation coefficient was obtained by 0.88 . In addition, the reliability of the test in the research on junior high school students of Zanjan was obtained through KuderRichardson for the sub-scale of processing, storage, and total as $0.85,0.84$, and 0.87 , respectively. Using KuderRichardson method, the reliability of the instrument in the present research was estimated as $0.82,0.80$, and 0.85 for the subscales of processing, storage, and total, respectively.

Sensory profile of Dunn (1999) for children aged 3 to 10 years old is the 125 -item questionnaire designed to describe the children's behavioral responses as visual, auditory, touch, motion, taste, and smelling drivers (stimulators) that are experienced as part of a child's daily activity. Further, these responses include nine sub-scales (e.g., auditory, visual, vestibular, touch, multisensory, oral sensory, and sensation processing associated with physical endurance/muscle consistency, along with the indoctrination related to the physical state of body motion). Likert scoring ranged from always (1) to never (5) based on the response from 1 to 5, respectively (33). This profile was conducted on the children aged 3-14 years at the first place and was investigated by Dunn (33) on children with behavioral problems at the second step as well, and its validity was confirmed accordingly. The main validity of the profiles was confirmed by the developers concerning the content and structure method. Furthermore, its reliability was reported as 0.77 and 0.91 , respectively, by the Cronbach $\alpha$ method for each section at the population of 1037 on-growing children (i.e., 424 girls and 510 boys), and the groups were considered at the age interval of 120 children (33). Bahri (34) confirmed the content and structure validity in Iran, and the reliability was obtained between 0.86 and 0.95 for the sub-scales and 0.96 for the total with regard to the Alpha Cronbach coefficient. The reliability was obtained between 0.84 to 0.92 for the subscales and 0.93 for the total in the Alpha Cronbach method at the present research.

\section{Results}

Regarding the demographic information of the boys, 11,23 , and 16 cases were eight, nine, and 10 years old. Moreover, the girls were within the age range of $8(n=19)$, $9(\mathrm{n}=21)$, and ten $(\mathrm{n}=18)$ years old. Additionally, 36 cases in the boy group had merely employed fathers, while 14 other children had employed parents. Finally, in the girl group, 47 children had merely employed fathers, whereas 11 children had employed parents.

Table 1 represents the values resulted from the descriptive indicators in both groups of working memory subscales and processing styles.

Due to the insignificance of the covariance homogeneity of Levene's test and the Box's test (0.521) related to the equality of the covariance matrices (Table 2), we could say that the data are consistent and the assumptions of multivariate analysis of variance (MANOVA) are observed as well.

Based on the result provided in Table 3, there was a significant difference in the writing disability according to the multivariate analysis of variance among processing $(P<0.006)$ and storage $(P<0.000)$ of working memory subscales and the indoctrination associated with the physical state of the body motion $(P<0.000)$, multisensory processing $(P<0.000)$, and auditory processing $(P<0.002)$ of the sensory profile in both girls and boys with writing disabilities. As shown in Table 2, no significant difference was observed between the two groups concerning the other subscales of sensory profile. Eventually, given the results of multiple sensory processing, the induction associated with the physical state of motion, memory storage, auditory

Table 1. Descriptive statistics of working memory and sensory profile in boys and girls with writing disability

\begin{tabular}{|c|c|c|c|c|}
\hline \multirow[t]{2}{*}{ Variable } & \multicolumn{2}{|c|}{$\begin{array}{l}\text { Boys Suffering from Writing } \\
\text { Disability }\end{array}$} & \multicolumn{2}{|c|}{$\begin{array}{l}\text { Girls Suffering from Writing } \\
\text { Disability }\end{array}$} \\
\hline & Mean \pm SD & $P$ Value & Mean \pm SD & $P$ Value \\
\hline Processing & $50.32 \pm 6.93$ & 0.002 & $54.22 \pm 7.45$ & 0.001 \\
\hline Storage & $48.47 \pm 6.08$ & 0.011 & $53.17 \pm 6.07$ & 0.008 \\
\hline Auditory processing & $31.74 \pm 5.84$ & 0.016 & $35.52 \pm 6.59$ & 0.001 \\
\hline Visual processing & $34.38 \pm 5.93$ & 0.014 & $35.01 \pm 7.61$ & 0.007 \\
\hline Vestibular processing & $34.62 \pm 6.14$ & 0.001 & $35.75 \pm 7.14$ & 0.006 \\
\hline Touch processing & $34.51 \pm 5.85$ & 0.001 & $29.63 \pm 5.81$ & 0.015 \\
\hline Multisensory processing & $34.68 \pm 5.21$ & 0.001 & $37.94 \pm 6.57$ & 0.004 \\
\hline Sensory-oral processing & $33.92 \pm 7.17$ & 0.002 & $35.02 \pm 6.39$ & 0.012 \\
\hline Sensory processing associated with physical endurance/muscle consistency & $34.50 \pm 5.43$ & 0.001 & $30.15 \pm 5.40$ & 0.002 \\
\hline Indoctrination associated with the physical state of the body motion & $34.28 \pm 7.09$ & 0.001 & $36.91 \pm 6.48$ & 0.003 \\
\hline Indoctrination of activity state affecting the motion & $35.22 \pm 5.91$ & 0.001 & $34.87 \pm 6.74$ & 0.004 \\
\hline
\end{tabular}


Table 2. The covariance homogeneity of Levene's test of working memory and sensory profile in boys and girls with writing disability

\begin{tabular}{|c|c|c|c|c|}
\hline Variable & $\boldsymbol{F}$ & df1 & $d f 2$ & $P$ Value \\
\hline Processing & 0.571 & 1 & 106 & 0.900 \\
\hline Storage & 0.486 & 1 & 106 & 0.972 \\
\hline Auditory processing & 0.721 & 1 & 106 & 0.676 \\
\hline Visual processing & 0.713 & 1 & 106 & 0.689 \\
\hline Vestibular processing & 0.816 & 1 & 106 & 0.519 \\
\hline Touch processing & 0.384 & 1 & 106 & 0.998 \\
\hline Multisensory processing & 0.727 & 1 & 106 & 0.665 \\
\hline Sensory-oral processing & 0.575 & & 106 & 0.895 \\
\hline Sensory processing associated with physical endurance/muscle consistency & 0.677 & 1 & 106 & 0.749 \\
\hline Indoctrination associated with the physical state of the body motion & 0.646 & 1 & 106 & 0.789 \\
\hline Indoctrination of activity state affecting the motion & 0.554 & 1 & 106 & 0.919 \\
\hline
\end{tabular}

Table 3. The results of multivariate analysis of variance regarding working memory and sensory profile in boys and girls with writing disability

\begin{tabular}{|c|c|c|c|c|c|}
\hline $\begin{array}{l}\text { Source of } \\
\text { Dispersion }\end{array}$ & Variables & Sum of Squares & $\begin{array}{l}\text { Mean of } \\
\text { Squares }\end{array}$ & $\begin{array}{l}\text { Variance } \\
\text { Analysis }\end{array}$ & $P$ Value \\
\hline \multirow{11}{*}{ Group } & Processing & 409.284 & 409.284 & 7.844 & 0.006 \\
\hline & Storage & 591.244 & 591.244 & 16.017 & 0.000 \\
\hline & Auditory processing & 379.621 & 379.621 & 9.682 & 0.002 \\
\hline & Visual processing & 10.904 & 10.904 & 0.230 & 0.623 \\
\hline & Vestibular processing & 36.046 & 36.046 & 0.803 & 0.372 \\
\hline & Touch processing & 3.117 & 3.117 & 0.077 & 0.782 \\
\hline & Multisensory processing & 619.300 & 619.300 & 18.183 & 0.000 \\
\hline & Sensory-oral processing & 43.192 & 43.192 & 1.206 & 0.275 \\
\hline & Sensory processing associated with physical endurance/muscle consistency & 44.469 & 44.469 & 0.971 & 0.327 \\
\hline & Indoctrination associated with the physical state of the body motion & 506.897 & 506.897 & 17.278 & 0.000 \\
\hline & Indoctrination of activity state affecting the motion & 3.601 & 3.601 & 0.078 & 0.780 \\
\hline
\end{tabular}

processing, and memory processing demonstrated the highest possible effect of the test in both groups associated with these visible components.

\section{Discussion}

Generally, the results revealed that there was a significant difference between female and male children with writinglearning disorder in terms of working memory and sensory processing styles. This is in line with the findings of Fathi Ashtiani et al (35), which indicated that the processing rate of working memory in male and female children with learning disabilities was different. Similarly, Amiri and Mousazadeh (36) found that active and passive avoidance systems, as well as shutdown avoidance system and conflict system, varied in teenagers. In addition, Peng and Fuchs (19) and Brandenburg et al (20) found a difference between the working memory in children with learning disorders among boys and girls and reported that the situation of memory and sensory processing of the girls was better than that of the boys. Likewise, Rodak and Alloway (21) showed a difference between girls and boys regarding writing disorders with the intensity of the deficiencies of working memory and sensory processing. Wolf et al (26) also demonstrated that girls with learning-writing disorders suffered from a lower cognitive deficiency as compared to boys, and the differences concerning hormonal and nervous system between the two genders were considered as the basic determinant for the existence of processing and the cognitive situation of the girls. Shaheedeh and Aghayousefi (37) reported that the difference between the activity amounts of brain processing systems among both genders creates a difference in determining the intensity of their disorder. In addition, the activity amount of the brain activation system was higher in individuals with an internal control resource and among the boys in comparison to the girls. They further concluded that the activity amount of the behavioral inhibition system was more in individuals with an external control resource, while this amount was higher in the girls in comparison to the boys. In the conflict-escape system, understanding the external control center showed a higher average and the girls' average in the escape was more compared to the boys, and thus the boys' average was different. Leong et al (25) found a difference in the composition of auditory and visual senses (eyesight) processing between male and female children with learning disorders. In this regard, 
Kasaeian et al (13) also indicated that the performance of working memory and the sustained attention of the students with writing-reading disabilities was significantly weaker than that of the normal students. It seems that stimulation facilitation and low sensory threshold in the boys positively predict the emotional-sensory processing, but a reduction in aesthetics sensitivity leads to a negative prediction (38).

Alloway and Temple (22) observed a difference between working memory skills and learning in female and male children with writing-learning disorders and concluded that the girls' working memory functioned better compared to that of the boys. Several studies reported that the intensity of working memory deficiency influences the background of learning disorder type and leads to the emergence of disorders in children $(23,24)$, which is in line with findings of other studies by Shiran and Breznitz (39) and Milton (40). According to the biological perspective, a better neurological and brain structural difference in the girls, which consistently causes the improvement of interactions with the social environment, can increase the improvement rate of disorders in interaction with the parent or teacher. Furthermore, both girls and boys have some differences in terms of the brain structure, some of which are in motion coordination, especially in auditory sense. The finding of this research indicates that both genders have some differences in sense processing. In addition, refered to some differences in the rate of processing and memory storage among the genders in line with this explanatory approach, the findings of which are in line with these issues. On the other hand, based on the socio-cultural perspective, the cause of many behaviors and even feedbacks related to physical biology can be perceived from cultural environments, and humans are affected by Such cultural environments. Therefore, based on this explanatory approach, the cultural difference in our society, which suggests that girls perform the behaviors and assignments more carefully than the boys, is manifested in the disorders as well. Therefore, new therapeutic interventions are suggested to be designed to repair the cognitive and sensory functions in children with written-learning disorders in collaboration with their parents.

The current research has some limitations. For example, the study included a limited population of children with learning disorders in Gorgan, which can be generalized only to this target group. Moreover, this research was a case-control study; therefore, it is hard to consider causality based on the collected information, and the findings may be due to multiple interactions between psychological and situational variables.

\section{Conclusion}

Based on the results of this study, a significant difference was observed regarding working memory and sensory processing styles in male and female children with the written-learning disorder, and the girls had a better situation compared to the boys in terms of sensory processing and working memory storage. These cognitive and processing failures can be attributed to a high degree of children's difficulties with learning disorders in such areas as reading, writing, and calculation. Eventually, the result of this study represented that boys with written-learning disorders had more deficiencies respecting cognitive and sensory functions compared to the girls.

Conflict of interests

None.

\section{Ethical considerations}

This research was registered with the institutional ethics code IR.IAU.AK.REC.1397.016 at Bandar Gaz Branch University.

\section{Acknowledgments}

We thank the director of Writing Disability Center for his collaboration in including the proper samples to the study. This research was registered under the code of 833.97.11.5522 at the State Welfare Organization of Gorgan in 2018. However, the organization provided no financial support for the research.

\section{References}

1. Goadsby PJ, Holland PR, Martins-Oliveira M, Hoffmann J, Schankin C, Akerman S. Pathophysiology of migraine: a disorder of sensory processing. Physiol Rev. 2017;97(2):553622. doi: 10.1152/physrev.00034.2015.

2. Mazzocco MM, Chan JY, Prager EO. Working Memory and Specific Learning Disability. In: Alloway TP, ed. Working Memory and Clinical Developmental Disorders. Routledge; 2018. p. 25.

3. Kong JE, Swanson HL. Working Memory and Specific Learning Disorders. In: Alloway TP, ed. Working Memory and Clinical Developmental Disorders. Routledge; 2018. p. 15.

4. Lerner JW, Egan RW, Lerner SR. Study Guide with Cases: Learning Disabilities: Theories, Diagnosis, and Teaching Strategies. Houghton Mifflin Company; 2003.

5. Lyon GR, Shaywitz SE, Shaywitz BA. A definition of dyslexia. Ann Dyslexia. 2003;53(1):1-14. doi: 10.1007/s11881-0030001-9.

6. Eskandari B, Pouretemad H, Habibi Asgarabad M, Mazaheri Tehrani MA. Effect of sensory processing style interventions on increasing parental self-efficacy and child-parent relationship in children with autism. Exceptional Education. 2016;1(138):14-21. [Persian].

7. Lane AE, Young RL, Baker AE, Angley MT. Sensory processing subtypes in autism: association with adaptive behavior. J Autism Dev Disord. 2010;40(1):112-22. doi: 10.1007/ s10803-009-0840-2.

8. Matsushima K, Kato T. Social interaction and atypical sensory processing in children with autism spectrum disorders. Hong Kong J Occup Ther. 2013;23(2):89-96. doi: 10.1016/j. hkjot.2013.11.003.

9. Adlparvar AH, Mazaheri MA, Sadeghi MS, Adlparvar A, Khodabakhsh $\mathrm{S}$. The relationship between sensory processing styles and marital satisfaction. Journal of Family Research. 2014;9(3):279-98. [Persian].

10. Jerome EM, Liss M. Relationships between sensory processing style, adult attachment, and coping. Pers Individ Dif. 2005;38(6):1341-52. doi: 10.1016/j.paid.2004.08.016.

11. Jagiellowicz J, Xu X, Aron A, Aron E, Cao G, Feng T, et al. 
The trait of sensory processing sensitivity and neural responses to changes in visual scenes. Soc Cogn Affect Neurosci. 2011;6(1):38-47. doi: 10.1093/scan/nsq001.

12. Aghajani N, HosseinKhanzadeh A, Kafi M. Effectiveness of $\mathrm{N}$-Back training software on working memory in students with dyslexia. J Learn Disabil. 2016;4(14):7-21.

13. Kasaeian K, Kiamanesh A, Bahrami H. A comparison of active memory performance and sustained attention among students with and without learning disabilities. J Learn Disabil. 2014;3(4):112-23.

14. Shokouhi-Yekta M, Lotfi S, Rostami R, Arjmandnia AA, Motamed-Yeganeh N, Sharifi A. The effect of cognitive training on the working memory performance of children with dyslexia. Audiology. 2014;23(3):46-56. [Persian].

15. Mills C, Chapparo C. Use of an in-class sensory activity schedule for a student with autism: critical case study. Creat Educ. 2016;7(7):979-89.

16. Swanson $\mathrm{HL}$, Jerman $\mathrm{O}$. The influence of working memory on reading growth in subgroups of children with reading disabilities. J Exp Child Psychol. 2007;96(4):249-83. doi: 10.1016/j.jecp.2006.12.004.

17. Kibby MY, Marks W, Morgan S, Long CJ. Specific impairment in developmental reading disabilities: a working memory approach. J Learn Disabil. 2004;37(4):349-63. doi: 10.1177/00222194040370040601.

18. Moll K, Gobel SM, Gooch D, Landerl K, Snowling MJ. Cognitive risk factors for specific learning disorder: Processing speed, temporal processing, and working memory. J Learn Disabil. 2016;49(3):272-81. doi: 10.1177/0022219414547221.

19. Peng P, Fuchs D. A meta-analysis of working memory deficits in children with learning difficulties: Is there a difference between verbal domain and numerical domain? J Learn Disabil. 2016;49(1):3-20. doi: 10.1177/0022219414521667.

20. Brandenburg J, Klesczewski J, Fischbach A, Schuchardt K, Buttner G, Hasselhorn M. Working memory in children with learning disabilities in reading versus spelling: Searching for overlapping and specific cognitive factors. J Learn Disabil. 2015;48(6):622-34. doi: 10.1177/0022219414521665.

21. Rodak J, Alloway TP. Developmental Coordination Disorder and Working Memory. In: Alloway TP, ed. Working Memory and Clinical Developmental Disorders: Theories, Debates and Interventions. London: Routledge; 2018.

22. Alloway TP, Temple KJ. A comparison of working memory skills and learning in children with developmental coordination disorder and moderate learning difficulties. Appl Cogn Psychol. 2007;21(4):473-87. doi: 10.1002/acp.1284.

23. Mammarella IC, Caviola S, Giofrè D, Szúcs D. The underlying structure of visuospatial working memory in children with mathematical learning disability. Br J Dev Psychol. 2018;36(2):220-35. doi: 10.1111/bjdp.12202.

24. Maehler C, Schuchardt K. Working memory in children with specific learning disorders and/or attention deficits. Learn Individ Differ. 2016;49:341-7. doi: 10.1016/j. lindif.2016.05.007.

25. Leong HM, Carter M, Stephenson JR. Meta-analysis of research on sensory integration therapy for individuals with developmental and learning disabilities. J Dev Phys Disabil. 2015;27(2):183-206. doi: 10.1007/s10882-014-9408-y.
26. Wolf $M$, Bowers PG, Biddle K. Naming-speed processes, timing, and reading: a conceptual review. J Learn Disabil. 2000;33(4):387-407. doi: 10.1177/002221940003300409.

27. Bogon J, Finke K, Schulte-Korne G, Muller HJ, Schneider WX, Stenneken P. Parameter-based assessment of disturbed and intact components of visual attention in children with developmental dyslexia. Dev Sci. 2014;17(5):697-713. doi: 10.1111/desc. 12150.

28. Kirby JR, Parrila RK, Pfeiffer SL. Naming speed and phonological awareness as predictors of reading development. J Educ Psychol. 2003;95(3):453-64. doi: 10.1037/00220663.95.3.453.

29. De Luca M, Burani C, Paizi D, Spinelli D, Zoccolotti P. Letter and letter-string processing in developmental dyslexia. Cortex. 2010;46(10):1272-83. doi: 10.1016/j.cortex.2009.06.007.

30. Romani C, Tsouknida E, di Betta AM, Olson A. Reduced attentional capacity, but normal processing speed and shifting of attention in developmental dyslexia: evidence from a serial task. Cortex. 2011;47(6):715-33. doi: 10.1016/j. cortex.2010.05.008.

31. Daneman M, Carpenter PA. Individual differences in working memory and reading. J Verbal Learning Verbal Behav. 1980;19(4):450-66. doi: 10.1016/S0022-5371(80)90312-6.

32. Asadzadeh $\mathrm{H}$. An investigation into the relationship between working memory capacity and academic performance among secondary school students in Tehran. Quarterly Journal of Education. 2009;1(97):53-70.

33. Dunn W. Sensory profile: user's manual. San Antonio, TX: Psychological Corporation; 1999.

34. Bahri A. The effect of sensory processing style training program according to Dunn's model on the mothers who have preschool children's in reducing symptoms of externalized disorder in children and mothers' stress [Thesis]. Tehran, Iran: Shahid Beheshti University; 2014.

35. Fathi Ashtiani M, Lotfi S, Rostami R, Arjmandnia AA, Motamed Yeganeh $N$, Sharifi A. The effectiveness of cognitive training on the processing rate and working memory of children with learning disabilities. Education Psychology. 2017;7:125-41.

36. Amiri M, Mousazadeh T. Comparison of Brain-Behavioral Systems in Normal and Delinquent Adolescents. Journal of Health. 2015;6(1):19-29. [Persian].

37. Shaheedeh M, Aghayousefi A. A comparison of brain inhibition / behavioral inhibition systems and control source of male and female students. Applied Psychology. 2013;6, 3(23):7-26.

38. Mahmoodi $\mathrm{N}$, Abdollahi MH, Shahgholian M, Gohari S. Mediating role of the positive and negative affect on the relationship between Sensory Processing Sensitivity and alexitimiya. Soc Cogn. 2015;4(7):28-40.

39. Shiran A, Breznitz Z. The effect of cognitive training on recall range and speed of information processing in the working memory of dyslexic and skilled readers. J Neurolinguistics. 2011;24(5):524-37. doi: 10.1016/j.jneuroling.2010.12.001.

40. Milton H. Effects of A Computerized Working Memory Training Program on Attention, Working Memory, And Academics. Adolescents with Severe ADHD/LD Psychology Journal. 2010;1(14):120-2. 